\title{
Nonalkolik yağlı karaciğer hastalığı olan bireylerde fruktoz tüketiminin değerlendirilmesi
}

\section{Evaluation of fructose consumption in individuals with non-alcoholic fatty liver disease}

\author{
Aliye KUYUMCU1*@, Tuğrul PÜRNAK2, Emine Akal YILDIZ
}

'Isparta Halk Sağlığı Müdürlüğü, Isparta/TÜRKiYE

${ }^{2}$ Hacettepe Üniversitesi Tıp Fakültesi, Gastroenteroloji ABD, Ankara/TÜRKIYE

${ }^{3}$ Doğu Akdeniz Üniversitesi Sağlık Bilimleri Fakültesi, Beslenme ve Diyetetik Bölümü, KKTC

\section{Öz}

Amaç: Bu çalışma, nonalkolik yağı karaciğer hastalığına (NAYKH) sahip bireylerin fruktozdan zengin besin tüketim düzeyini belirlemek ve bu düzeyin, biyokimyasal parametreler ile antropometrik ölçümlerle olası ilişkisini saptamak amacıyla yürütülmüştür.

Gereç ve Yöntemler: Batın ultrasonografi (USG) ile karaciğerde farklı derecelerde yağlanma tespit edilen 19-65 yaş arası bireyler; hafif steatoz (grade 1, n=15), orta steatoz (grade $2, n=15$ ), şiddetli steatoz (grade $3, n=15$ ) ve tetkiklerinde steatoz saptanmamış olan (grade $0, n=15$ ) olarak 4 gruba ayrılmıştır. Bireylere fruktozdan zengin besin tüketim sıklığı formu ve 24 saatlik besin tüketim kaydı uygulanmıştır. Hepatosteatoz derecesi ile bireylerin antropometrik ölçümleri, bazı biyokimyasal bulguları, fiziksel aktivite durumları ve fruktozdan zengin beslenme durumları arasındaki ilişkiye bakılmıştır.

Bulgular: Bu çalışmada BKi, bel çevresi, bel/kalça oranı gibi antropometrik ölçümler, steatoz derecelerinin artışıyla birlikte artmıştır ve istatistiksel açıdan önemlidir $(p<0.001)$. Fiziksel aktivite düzeyinde, gruplar arasında önemli bir fark yoktur ( $p=0,099$ ). Besinlerle alınan günlük fruktoz miktarları, grade 0'da en düşük; grade 2 ve grade 3 grubunda benzer miktarlarda ve diğer gruplara göre yüksektir $(p<0,001)$. Fruktozdan zengin alkolsüz gazlı içecek türlerinin (gazoz ve kolalı içecek) günlük tüketim ortalamaları ise grade $0(8,7 \pm 5,7 \mathrm{ml})$ grubunda en az, grade $3(291 \pm 33,5 \mathrm{ml})$ grubunda ise önemli düzeyde yüksek bulunmuştur ( $p=0,001)$. Ayrıca, çalışmada bireylerin fruktoz tüketimi ile**BKi , **bel çevresi , *bel/kalça oranı, * total kolesterol, **ürik asit, ${ }^{* *}$ ALT $,{ }^{*} A S T,{ }^{* *}$ ALP, ${ }^{* *}$ çikolata tüketim miktarı, **hazır meyve suyu, *alkolsüz gazlı içecek tüketimleri arasında önemli pozitif bir ilişki saptanmıştır $\left({ }^{*} p<0,05,{ }^{* *} p<0,01\right)$.

Sonuç: Çalışmamızda NAYKH sahip bireylerde steatoz derecesi ile fruktoz tüketimi arasında kuvvetli düzeyde ilişki bulunmuştur. Besinlerle vücuda alınan fruktozun aşıı tüketimi, başta obezite olmak üzere alkolik olmayan karaciğer yağlanması, metabolik sendrom ve kalp damar hastalıkları gibi hastalıklar için risk oluşturabileceği göz önünde bulundurulmalıdır. Fruktozun, günlük diyette tüketimi doğal kaynaklardan sağlanmalı ve aşııı tüketiminden kaçınılmalıdır.

Anahtar kelimeler: nonalkolik yağlı karaciğer hastalığı; fruktoz; yüksek fruktozlu mısır şurubu; beden kitle indeksi

Sorumlu Yazar*: Aliye Kuyumcu, Isparta Halk Sağlığı Müdürlüğü, Isparta/TÜRKiYE

E-posta: aliye_poslu@hotmail.com

ORCID: 0000-0002-6830-1534

Gönderim : 05.02.19 Kabul: 25.02.2019

Doi: $10.18663 /$ tjcl.522720 


\begin{abstract}
Aim: The aim of this study was to determine fructose-rich food consumption levels of individuals with nonalcoholic fatty liver disease (NAYKH) and to determine the possible relationship between biochemical parameters and anthropometric measurements.
\end{abstract}

Material and Methods: Individuals between 19-65 years of age with abdominal ultrasonography (USG) with varying degrees of fatty tissue; mild steatosis (grade 1, $n=15$ ), moderate steatosis (grade 2, $n=15$ ), severe steatosis (grade 3, $n=15$ ) and no steatosis (grade $0, n=15$ ). Nutritional status and 24-hour nutrient consumption were recorded. Anthropometric measurements of individuals, some biochemical findings, physical activity status and fructose-rich nutrition status were investigated.

Results: In this study, anthropometric measurements such as BMI, waist circumference and waist/hip ratio increased with the increase in steatosis degrees and were statistically significant $(p<0.001)$. At physical activity level, there is no significant difference between groups ( $p=0,099$ ). Daily fructose intake with nutrients is the lowest in grade 0; Grade 2 and Grade 3 groups have similar amounts and higher than other groups $(\mathrm{p}<0.001)$. The average daily consumption of fructose-rich nonalcoholic beverages (soda and cola) was found to be at least in grade $0(8.7 \pm 5.7 \mathrm{ml})$ and significantly higher in grade 3 (291 $\pm 33.5 \mathrm{ml}),(p=0,001)$. Furthermore, in the study individuals with fructose consumption ${ }^{* *} \mathrm{BMl},{ }^{* *}$ waist circumference, ${ }^{*}$ waist / hip ratio, * total cholesterol, ${ }^{* *}$ uric acid, ${ }^{* *}$ ALT, ${ }^{*}$ AST, ${ }^{* *}$ ALP, ${ }^{* *}$ chocolate consumption amount, ${ }^{* *}$ a significant positive relationship was found between the consumption of ready-made fruit juice and alcoholic beverages $\left({ }^{*} p<0.05,{ }^{* *} p<0.01\right)$.

Conclusion: In our study, there was a strong correlation between the degree of steatosis and fructose consumption in individuals with NAYKH. It should be kept in mind that excessive consumption of fructose with nutrients may pose a risk for diseases such as obesity, non-alcoholic fatty liver, metabolic syndrome and cardiovascular diseases. The consumption of fructose in daily diet should be provided from natural sources and excessive consumption should be avoided.

Keywords: nonalcoholic fatty liver disease; fructose; high fructose corn syrup; body mass index

\section{Giriş}

Nonalkolik yağlı karaciğer hastalığı (NAYKH), son dönem karaciğer hastalığına ilerleme gösteren, her geçen gün önemi daha da fazla fark edilen klinik ve patolojik bir durumdur [1]. NAYKH, karaciğere zarar verecek miktarda alkol tüketimi olmayan bireylerde (kadınlarda <10-20 g/gün, erkeklerde $<20-40$ g/gün) histolojik olarak makro vesiküler yağlanmanın baskın olduğu geniş bir tabloyu içerir [2]. NAYKH'nin, en yaygın Amerika'da görüldüğü ve ülkemize ait yeterli istatistiklerin bulunmamasına karşın bugün batı toplumlarında hastalığın genel prevalansının \%10-24 olduğu bildirilmektedir [3, 4]. Özellikle batı toplumlarında NAYKH, 5 yıllık gözlem sonucunda sağlık harcamalarını doğrudan veya dolaylı olarak yaklaşık \%26 oranında artırdığı bildirilmiştir [5]. Hastalığa ait patogenez, uzun yıllardır 'Çift vuruş' hipotezi olarak adlandırılan bir modelle açıklanmaya çalışılmaktadır [1]. Çift vuruş teorisi, basit steatozdan non-alkolik steatohepatit, fibrozis ve siroza doğru ilerleyen süreci en iyi ifade eder. Bu çift vuruşlar insülin direnci (ID) nedeniyle karaciğerde aşırı yağ birikmesi ve reaktif oksijen türleri nedeniyle oksidatif stresin birleşiminden oluşur.
Bu teoride birinci vuruş olan steatoz oluşumunda tip 2 diyabet (DM) ve obezitede sıklıkla bulunan insülin direnci anahtar rol oynamaktadır [6].

Günümüzde NAYKH tedavisi; hiperlipidemi, diyabet, obezite gibi risk faktörlerini değiştirmeye odakladır. Çoğu olguda tedavi amacı 6 aydan fazla bir sürede vücut ağırlığının \%10'u kadar ağırlık kaybetmeyi başarmak ve bunu sürdürmektir. Kilo kaybının sürekliliği için yeterli-dengeli bir diyet ve egzersiz, tedavinin birer parçası olmalıdır [6].

Insanlar yüzlerce yıl fruktozu ortalama 16-20 g/gün olacak şekilde diyetlerinde çoğunlukla taze meyveler ile sağlarlarken, batı tarzı diyete yönelimin artması ile fruktoz tüketiminde önemli artış görülmüştür. Günümüzde Batılıların diyetlerinde enerjinin yaklaşık \%15-20'sinin kaynağı fruktozdur (yaklaşık 85-100 g/gün) [7]. Fruktozun en önemli kaynağı, sükroz (\%50 glikoz, \%50 fruktoz) ve yüksek fruktozlu mısır şurubu (HFCS)'dur. HFCS 1970'li yıllarda yiyecek ve içecek endüstrisi için, sükroza alternatif ve maliyeti daha düşük olarak üretilen bir fruktoz-glikoz sıvı tatlandırıcı olarak üretilmeye başlamıştır. Günümüzde HFCS, sükrozun yerini alarak başta kolalı içecekler 
olmak üzere gazozlar, sodalar vb. alkolsüz içecekler ve hazır gıda ürünlerin üretiminin birçoğunda (bisküvi, çikolata, şekerleme, kek, kahvaltılık gevrekler gibi) kullanılmaktadır [8]. Birçok epidemiyolojik, klinik ve deneysel çalışmada meyvelerin içinde doğal olarak bulunan ve meyve şekeri olarak bilinen fruktozun, son 30 yılda gıda sanayisinin en çok kullandığı tatlandıııc haline gelmesinin ve artan tüketiminin obezite, insülin direnci, bozulmuş glikoz toleransı, tip 2 diyabet (DM), hiperlipidemi, alkolik olmayan karaciğer yağlanması, hiperürisemi, gut ve metabolik sendrom gibi hastalıkların ilintili olabileceğini düşündürmüştür [9-12]. Ayrıca fruktozdan zengin diyetin inflamasyonu arttırdığına dair literatürde bulgular bulunmaktadır ve inflamasyon kardiyovasküler hastalıklara yol açan önemli bir risk faktörüdür [13, 14].

Bu çalışma; NAYKH tanısı almış bireylerde fruktozdan zengin besinlerin tüketim düzeyini belirlemek ve bu düzeyin biyokimyasal parametreler ile antropometrik ölçümlerle ilişkisini saptamak amacıyla planlanmıştır.

\section{Gereç ve Yöntemler}

Bu araştırma, 2012-2013 yılları arasında çeşitli şikayetlerle Ankara Numune Eğitim ve Araştırma Hastanesi gastroenteroloji polikliniğine başvuran ve batın ultrasonografide farklı derecelerde grade1 (hafif), grade 2 (orta derece), grade 3 (şiddetli) yağlanma tespit edilen 19-65 yaş arası 45 hasta ve aynı polikliniklere çeşitli şikayetlerle başvurup USG tetkiklerinde steatoz saptanmamış 15 sağlıklı birey üzerinde yürütülmüştür. Araştırma gastroenterolog, diyetisyen ile multidisipliner bir şekilde yürütülmüştür. Bireylerden antropometrik ölçümler, fiziksel aktivite kaydı ve bir günlük besin tüketim kaydı ve biyokimyasal bulgular alınmıştır. Bireylere son bir aylık süreci içerecek şekilde diyetlerinde fruktoz içeren bazı besinlerin tüketim sıkığı sorgulanmış ve bir günlük (24 saatlik) besin tüketimi kayıtları alınmıştır. Fiziksel aktivite düzeyleri, fiziksel aktivite kaydı ile değerlendirilmiştir. Antropometrik ölçümleri (boy uzunluğu, vücut ağırlığı, bel çevresi ve kalça çevresi) alınmışır. Bireylerin plazma glukoz, insülin, aspartataminotransferaz (AST), alani $\neg$ naminotransferaz [5], triiodotironin (T3), serbest tiroksin (T4), troid stimülan hormon (TSH), alkalen fosfataz (ALP), gama glutamiltransferaz (GGT), üre, ürik asit, kreatinin, yüksek dansiteli lipoprotein-kolesterol (HDL-K), düşük dansiteli lipoprotein-kolesterol (LDL-K), çok düşük dansiteli lipoprotein-kolesterol (VLDL-K), trigliserit (TG), total kolesterol düzeyleri ile serumda hepatit $B(\mathrm{HBs} A g)$, anti hepatit C (HCV) ve hepatobiliyer USG sonuçları kaydedilmiştir. Alkol kullanma öyküsü (bayan>10g/gün, erkek>20g/gün ) ve $\mathrm{HBs}$ Ag veya Anti HCV pozitifliği olan, otoimmün hepatit, Wilson hastalığı, malignensi, kortikosteroid, metotreksat, tamoksifen ve oral kontraseptif gibi sürekli ilaç kullanımı, jejunoileal bypass veya geniş ince barsak rezeksiyonu, kalp-böbrek yetmezliği, hemakromatozis veya diğer kronik karaciğer hastalıkları saptanan, hamile, troid fonksiyon bozukluğu, insülin veya oral anti-diyabetik tedavisi alan diyabetik hastalar çalışma dışı bırakılmıştır. Bu çalışma için gerekli Etik Kurul izinleri alınmıştır. Katılımcılardan gönüllü onam formu alınmıştır.

\section{Bel çevresi:}

Iliak çıkıntı ile en alt kaburga kemiğinin ortasındaki en düşükçevre ölçümü, 0,01 cm duyarlı esnemeyen mezur ile alınmıştır [15]. Erkeklerde $\geq 94 \mathrm{~cm}$ risk ve $\geq 102 \mathrm{~cm}$ yüksek risk olarak, kadınlarda ise $\geq 80 \mathrm{~cm}$ risk ve $\geq 88 \mathrm{~cm}$ yüksek riskli kabul edilmiştir [16].

\section{Kalça çevresi:}

Kalça üzerindeki en geniş çevrenin ölçümü $0,01 \mathrm{~cm}$ duyarlı esnemeyen mezur ile alınmıştır [15] .

\section{Bel/kalça oranı (BKO):}

Bel çevresi $(\mathrm{cm}) /$ kalça çevresi $(\mathrm{cm})$ formülü ile hesaplanmıştır. Erkeklerde $<1$ ve kadınlarda $<0,85$ normal değer kabul edilmekte, bu değerlerin üzerinde ise obezite tanısı almışıı [17].

\section{Beden Kütle İndeksi (BKi):}

Vücut ağırlığı $(\mathrm{cm})$ ve boy uzunluğu $(\mathrm{cm})$ ölçümleri alınarak BKi değerleri $(\mathrm{kg} / \mathrm{m} 2)$ hesaplanmıştır. BKi 18,5-25 arasında olanlar normal, BKi 25-29,9 arasında olanlar hafif kilolu, BKi >30un üzerinde olanlar obez olarak değerlendirilmiştir [17] .

\section{Fiziksel Aktivite Kaydı:}

Bireylerin günlük gruplandırımış fiziksel aktivite türleri ve süreleri kayıt edilmiştir. Bireylerin bazal metabolik hız (BMH) değerleri, yaş gruplarına ve cinsiyete göre belirlenmiş Schofield (1985) denklemi [18] ile hesaplanmıştır. Fiziksel aktivite türleri için belirlenmiş olan fiziksel aktivite oranı (PAR) değerleri ile bireylerin kayıt ettiği aktivite süreleri çarpılmıştı. Bu veri, bazal metabolizma hızlarının 1440 dakikaya bölünmesi ile elde edilen değerle çarpıImış ve bireylerin günlük toplam enerji harcamaları (günlük toplam enerji harcamaları TEH) elde edilmiştir. Fiziksel aktive düzeyleri (PAL) [19] ise, toplam enerji harcamasının bazal metabolizma hızına oranlanması ile belirlenmiştir [20].

\section{Hepatobiliyer Ultrasonografi}

Ankara Numune Eğitim ve Araştırma Hastanesi Gastroenteroloji Kliniği' nde tek bir cihaz üzerinde yapılmış olup yağlanma tespitinde aşağıdaki kriterler esas alınmıştır:

1. Hafif steatoz (grade 1): Hepatik ekojenitede minimal diffüz artış; intrahepatik damarların kenarları ve diyafragma normalde olduğu gibi görülebiliyor.

2. Orta derecede steatoz ( grade 2) : Hepatik ekojenitede orta düzeyde artış; intrahepatik damarların kenarları ve diyafragma çok iyi görülemiyor. 
3. Şiddetli steatoz (grade 3): Ekojenitede belirgin artış, karaciğer sağ lobunun posterior segmentine sesin penetre olamaması veya hepatik damarların, diyafragmanın görülemiyor [21] .

\section{İstatistiksel Analiz}

Analizlerde, SPSS 20.0 istatistik paketi (SPSS Inc., Chicago, II, ABD) kullanılmıştır. Ölçümle elde edilen sürekli değişkenler (nicel değişkenler), ortalama, standart sapma, alt ve üst değerleri ile sunulmuştur. Bireylerin anket formuna verdikleri cevaplardan kategorik değişkenlerin (nitel değişkenler) sunumu için ise frekans ve yüzde değerler kullanılmıştır. Sayısal verilerin normal dağılım gösterip göstermediği Kolmogorov Smirnov testi ile belirlenmiştir. Niteliksel veriler arasında ilişkilerin araştırılması için Ki-Kare testi kullanılmıştır. Bireylerden elde edilen niteliksel verilerin karşılaştırılması ve gruplar arasındaki farklılıkların araştırılmasında, tablolarda 5'den küçük veri bulunan göz sayısının, toplam göz sayısının \%20' sini aşmadığı durumlarda Pearson Ki-kare, aştığı durumlarda ise Fisher'in kesin ki-kare testi uygulanmıştır. Niceliksel iki grubun karşılaştırılması amacıyla parametrik test koşullarının sağlanmadığı durumlarda ise Mann-Whitney U testi, üç veya daha fazla grubun karşılaştırılmasında ise Kruskall
Wallis analizi kullanılmıştır. Bütün istatistiksel analizlerde önemlilik düzeyi olarak $p<0,05$ ve/veya $p<0,001$ olarak kabul edilmiştir . İki ya da daha çok sayısal değişken arasında ilişki olup olmadığını ve gücünü korelasyon analizi (Pearson) ile, biri iki kategorili niteliksel, diğeri sürekli sayısal veri türünde olanında ise Eta korelasyon katsayısı kullanılmıştır .

\section{Bulgular}

Grupların demografik özellikleri, antropometrik ölçümleri, fiziksel aktivite durumu ve biyokimyasal bulguları Tablo 1 'de verilmiştir. Hepatosteatoz görülmeyen grubu yaş ortalaması en düşük, steatozu bulunan gruplardaki bireylerin yaş ortalamalarının benzer olduğu görülmüştür $(p<0,05)$. BKi, bel çevresi, bel/kalça oranı yağlanma dereceleri artıkça artmıştır ve tüm gruplarda bu farklılık istatistiksel açıdan önemlidir $(p<0,001)$. Hepatosteatozu olmayan gruptaki bireyler daha aktif olmakla birlikte, tüm gruplardaki bireyler sedenter/hafif aktivite düzeyine sahiptir $(p<0,001)$. Biyokimyasal bulgulara bakıldığında ise ürik asit, trigliserit, total kolesterol, VDLD, LDL, ALT, AST, GGT ve ALP düzeyleri gruplar arası farklılıkgöstermekte ve bu farklılık istatistiksel olarak önemlidir $(p \leq 0,001)$.

\begin{tabular}{|c|c|c|c|c|c|}
\hline & Grade 0 (n:15) & Grade 1 (n:15) & Grade 2 (n:15) & Grade 3 (n:15) & $p$ \\
\hline \multicolumn{6}{|l|}{ Demografik özellik } \\
\hline Yaş, yıl & $34 \pm 9,2$ & $46 \pm 11,1$ & $48 \pm 11,3$ & $47 \pm 12,4$ & $<0,05$ \\
\hline Erkek/Kadın, n\% & $\% 26,7 / 73,3$ & $\% 26,7 / 73,3$ & $\% 33,3 / 66,7$ & $\% 26,7 / 73,3$ & 0.812 \\
\hline Hipertansiyon, n/\% & - & $5 / 33,3$ & $5 / 33,3$ & $4 / 26,7$ & 0.785 \\
\hline Aile DM öyküsü,n/\% & $3 / 20$ & $6 / 40$ & $9 / 60$ & $9 / 60$ & 0.458 \\
\hline \multicolumn{6}{|l|}{ Antropometrik ölçüm } \\
\hline BKi $(\mathrm{kg} / \mathrm{m} 2)$ & $24,6 \pm 3,3$ & $29,9 \pm 3,2$ & $35 \pm 6,4$ & $39 \pm 8,2$ & $<0,001$ \\
\hline Bel çevresi (cm) & $83,8 \pm 9,1$ & $104,6 \pm 8,5$ & $116 \pm 9,1$ & $118 \pm 12,5$ & $<0,001$ \\
\hline Bel/kalça oranı & $0,89 \pm 0,04$ & $0,99 \pm 0,07$ & $1,01 \pm 0,05$ & $0,99 \pm 0,07$ & $<0,001$ \\
\hline \multicolumn{6}{|l|}{ Fiziksel aktivite } \\
\hline PAL & $1,67 \pm 0,12$ & $1,60 \pm 0,13$ & $1,48 \pm 0,07$ & $1,46 \pm 0,06$ & $<0,001$ \\
\hline $\mathrm{BMH}(\mathrm{kkal})$ & $1430,8 \pm 179,8$ & $1414,8 \pm 130,1$ & $1560,7 \pm 233,4$ & $1484,8 \pm 164,7$ & 0,125 \\
\hline TEH(kkal) & $2405,4 \pm 413,9$ & $2266 \pm 307,8$ & $2329,7 \pm 429,8$ & $2176,5 \pm 258,7$ & 0,438 \\
\hline \multicolumn{6}{|l|}{ Biyokimyasal bulgular } \\
\hline Glikoz(mg/dL) & $92 \pm 4,9$ & $98,2 \pm 10,6$ & $109 \pm 20,4$ & $97,5 \pm 13,5$ & 0,013 \\
\hline Ürik asit(mg/dL) & $3,9 \pm 0,61$ & $4,9 \pm 0,79$ & $5,9 \pm 1,1$ & $6,1 \pm 1,07$ & $<0,001$ \\
\hline Trigliserit(mg/dL) & $82,2 \pm 25,7$ & $171 \pm 118,2$ & $174 \pm 58,7$ & $173 \pm 40,5$ & $<0,001$ \\
\hline Total Kolesterol(mg/dL) & $139 \pm 33,5$ & $201 \pm 28,0$ & $191 \pm 49,2$ & $175 \pm 46,9$ & 0,001 \\
\hline $\mathrm{HDL}(\mathrm{mg} / \mathrm{dL})$ & $54,6 \pm 7,6$ & $53,9 \pm 13,3$ & $44,6 \pm 11,3$ & $47,1 \pm 11,9$ & 0,018 \\
\hline $\mathrm{LDL}(\mathrm{mg} / \mathrm{dL})$ & $92,4 \pm 11,6$ & $114 \pm 23,8$ & $114 \pm 37,5$ & $104,9 \pm 49$ & 0,130 \\
\hline $\operatorname{VLDL}(\mathrm{mg} / \mathrm{dL})$ & $16,4 \pm 7,4$ & $34,4 \pm 23,6$ & $34,8 \pm 11,8$ & $31,8 \pm 15,1$ & 0,001 \\
\hline $\mathrm{ALT}(\mathrm{U} / \mathrm{L})$ & $14,8 \pm 5,7$ & $32 \pm 20,5$ & $49,7 \pm 54,5$ & $50,6 \pm 22,0$ & $<0,001$ \\
\hline $\mathrm{AST}(\mathrm{U} / \mathrm{L})$ & $23 \pm 16,7$ & $29,7 \pm 14,9$ & $30 \pm 28,5$ & $40,7 \pm 22,0$ & $<0,001$ \\
\hline GGT(U/L) & $42 \pm 16,8$ & $30,6 \pm 18,3$ & $45,3 \pm 27,6$ & $59 \pm 63,6$ & $<0,001$ \\
\hline$A L P(U / L)$ & $50,8 \pm 15,4$ & $73 \pm 22,1$ & $81,4 \pm 19,2$ & $83,6 \pm 19,5$ & $<0,001$ \\
\hline
\end{tabular}


Tablo 2'e göre bireylerin günlük diyetleriyle tükettikleri fruktozdan zengin besinlerin fruktoz, sukroz miktarları ve fruktozun kaynaklarına göre dağılımları dağılımı belirtilmiştir. Grade 0 grubunun günlük ortalama fruktoz tüketimi 14,1 $\pm 8,3$

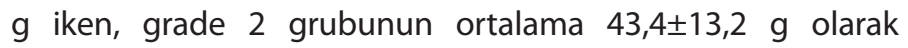
hesaplanmıştır $(p<0,001)$. Fruktoz ve sükroz tüketimlerine bakıldığında ise grade 3 grubundaki bireylerin en yüksek tüketime sahip olduğu, günlük besinlerle alınan enerjinin \% $7,8 \pm 2,87$ 'inin fruktoz ve $\% 17,9 \pm 5,56$ 'sinin sükrozdan geldiği gözlenmiştir. Alkolsüz gazlı içecek türleri (gazoz ve kolalı içecek) tüketim ortalamaları değerlendirildiğinde tüketimin en az olduğu grade 0 grubunda $(8,7 \pm 5,7 \mathrm{ml})$ olduğu, hepatosteatoz olan gruplardaki tüketiminin ise sırasıyla grade $1=100 \pm 255,2 \mathrm{ml}$, grade $2=106,3 \pm 93,7 \mathrm{ml}$, grade $3=291 \pm 335,55 \mathrm{ml}$ dir $(p=0,001)$. Fruktozun önemli doğal kaynaklarından olan meyve tüketimi ise yine grade 2 (ortalama: $757 \pm 313,1 \mathrm{~g}$ ) ve grade 3 (ortalama: $706,6 \pm 467 \mathrm{~g}$ ) grubundaki bireylerde fazla miktardadır.

\begin{tabular}{|c|c|c|c|c|c|}
\hline & Grade 0 (n:15) & Grade 1 (n:15) & Grade 2 (n:15) & Grade 3 (n:15) & $\mathrm{p}$ \\
\hline \multicolumn{5}{|l|}{ Fruktoz kaynakları } & \multirow{2}{*}{0.064} \\
\hline Çikolata (g) & $2.0 \pm 2.1$ & $10.0 \pm 11.9$ & $8.6 \pm 13.6$ & $8.8 \pm 7.2$ & \\
\hline Hazır kek (g) & $1.7 \pm 2.6$ & $5.9 \pm 6.1$ & $11.6 \pm 12.7$ & $11.7 \pm 8.8$ & $<0.001$ \\
\hline Şekerli bisküvi(g) & $1 \pm 2.8$ & $2.8 \pm 4.7$ & $14 \pm 24.1$ & $6.6 \pm 7.2$ & 0.006 \\
\hline Şekerleme (g) & $6 \pm 7.8$ & $1.2 \pm 2.6$ & $2.4 \pm 2.9$ & $5.1 \pm 6.9$ & 0.174 \\
\hline Bal, reçel, pekmez(g) & $7.2 \pm 8.9$ & $10.7 \pm 14.1$ & $18.1 \pm 12.9$ & $22.1 \pm 10.9$ & 0.001 \\
\hline Çay şekeri (g) & $6.1 \pm 7.8$ & $16.5 \pm 18.9$ & $24.8 \pm 21.2$ & $33.6 \pm 26.2$ & 0.174 \\
\hline Sebze $(g)$ & $180 \pm 107.5$ & $179 \pm 163.3$ & $141.3 \pm 78.9$ & $119.3 \pm 64.1$ & 0.617 \\
\hline Meyve (g) & $256 \pm 225.7$ & $260 \pm 216.2$ & $757 \pm 313.1$ & $706.6 \pm 467$ & $<0.001$ \\
\hline Hazır meyve suyu(ml) & $4.6 \pm 8.5$ & $29 \pm 51.7$ & $123.6 \pm 136.2$ & $56 \pm 100.1$ & $<0.001$ \\
\hline Alkolsüz gazlı içecek (ml) & $8.7 \pm 5.7$ & $100 \pm 255.2$ & $106.3 \pm 93.7$ & $291 \pm 335.5$ & 0.001 \\
\hline Soğuk Çay (ml) & $3.4 \pm 8.3$ & $6.7 \pm 15.2$ & $8.7 \pm 20.2$ & $13.3 \pm 27.2$ & $<0.001$ \\
\hline Meyveli Soda(ml) & $5 \pm 11.5$ & $25,6 \pm 55.6$ & $31.3 \pm 55.5$ & $38.3 \pm 60.2$ & 0.174 \\
\hline Çözünebilir kahve (g) & $3.3 \pm 9.2$ & $4.7 \pm 9.8$ & $14.3 \pm 17.4$ & $5.6 \pm 6.6$ & 0.015 \\
\hline Fruktoz(g) & $14.1 \pm 8.3$ & $18.5 \pm 10.3$ & $43.4 \pm 13.2$ & $42.0 \pm 13.5$ & $<0.001$ \\
\hline Fruktoz(TEG\%) & $2.5 \pm 1.60$ & $3.3 \pm 1.88$ & $7.5 \pm 2.39$ & $7.8 \pm 2.87$ & $<0.001$ \\
\hline Sükroz(g) & $21.0 \pm 13.4$ & $44.4 \pm 30.5$ & $80.9 \pm 37.2$ & $97.7 \pm 32.7$ & $<0.001$ \\
\hline Sükroz(TEG\%) & $3.6 \pm 2.51$ & $7.8 \pm 5.41$ & $14.2 \pm 7.34$ & $17.9 \pm 5.56$ & $<0.001$ \\
\hline
\end{tabular}

Bireylerin fruktoz tüketimleri ile çeşitli değişkenler arasındaki ilişkiye bakıldığında Tablo 3'e göre, BKi ( $r=0.446, p<0.001)$, bel çevresi $(r=0.504, p<0.001)$, bel/kalça oranı $(r=0.308, p=0.017)$, total kolesterol $(r=0.274, p=0.034)$, ürik asit $(r=0.383, p=0.003)$, $\operatorname{ALT}(r=0.353, p=0.006), \operatorname{AST}(r=0.269, p=0.038), \operatorname{ALP}(r=0.508$, $p<0.001)$, çikolata tüketim miktarı ( $g)(r=0.345, p=0.007)$, hazır meyve suyu $(\mathrm{ml})(r=0.424, p=0.001)$ ve alkolsüz gazlı içecek $(r=$ 0.294, $p=0.023$ ) arasında önemli pozitif ilişki bulunmaktadır. Ayrıca, hepatosteatoz derecesi, fruktoz tüketimi ile kuvvetli düzeyde ilişkilendirilmiştir ( $r=0.979)$.

\begin{tabular}{|c|c|c|c|}
\hline \multirow[b]{2}{*}{ Değişkenler } & \multicolumn{2}{|c|}{$\begin{array}{l}\text { Fruktoz Tüketimi } \\
\text { (g/gün) }\end{array}$} & \\
\hline & $r$ & $p$ & \\
\hline Yaş (yıl) & 0.243 & 0.062 & \\
\hline BKi $(\mathrm{kg} / \mathrm{m} 2)$ & 0.446 & $<0.001^{* *}$ & \\
\hline Bel çevresi (cm) & 0.504 & $<0.001^{* *}$ & \\
\hline Bel/kalça oranı(cm) & 0.308 & $0.017^{*}$ & \\
\hline Açlık glikoz (mg/dl) & 0.197 & 0.132 & \\
\hline Total kolesterol(mg/dl) & 0.274 & $0.034^{*}$ & \\
\hline LDL -K(mg/dl) & 0.216 & 0.097 & \\
\hline HDL-K(mg/dl) & -0.171 & 0.216 & ${ }^{*} \mathrm{p}<0.05,{ }^{* *} \mathrm{p}<0.01$ \\
\hline TG (mg/dl) & 0.204 & 0.117 & \\
\hline Ürik asit(mg/dl) & 0.383 & 0.003 & \\
\hline ALT(U/L) & 0.353 & $0.006^{* *}$ & \\
\hline AST(U/L) & 0.269 & $0.038^{*}$ & \\
\hline ALP(U/L) & 0.508 & $<0.001^{* *}$ & \\
\hline Çikolata tüketimi(g) & 0.345 & $0.007^{* *}$ & \\
\hline Hazır meyve suyu(ml) & 0.424 & $0.001^{* *}$ & \\
\hline Kolalı içecekler(ml) & 0.294 & $0.023^{*}$ & \\
\hline Hepatosteatoz derecesi & $0.979 * * *$ & $<0.001^{* *}$ & \\
\hline
\end{tabular}




\section{Tartışma}

Non-alkolik karaciğer yağlanması, son yıllarda tüm dünyada önemi gittikçe artmakta ve batı toplumlarında sık görülen bir patolojidir. NAYKH'nın klinik önemi, genel popülasyonda sık görülmesinden siroza ve karaciğer yetmezliğine ilerleme ihtimalinden kaynaklanmaktadır.

Son 30 yılda, meyvelerin içinde doğal olarak bulunan ve meyve şekeri olarak bilinen fruktoz gıda sanayisinin en çok kullandığı tatlandırıc haline gelmiştir. Doğal yiyeceklerle alımı yararlı olan bu şeker türünün gıda sanayisindeki kullanımı arttıkça, doğal olmayan yollardan fazla tüketiminin beslenmeye bağlı hastalıklara (obezite, alkolik olmayan karaciğer yağlanması, gut ve metabolik sendrom gibi) yol açabileceğine dikkat çekilmiştir [22]. HFCS' nin aşırı tüketimi (öncelikle alkolsüz gazlı içecek formları) ağırlık kazanımı-obezite ve artmış NAYKH riski ile ilişkilendirilmektedir [22]. Bray ve ark. [23] Amerika' da yaşayan iki yaş üzeri bireyler üzerinde yaptığı çalışmada, bireylerin ortalama günlük 132 kaloriyi HFCS' den ve ortalama 318 kkal ise diyete eklenen tatlandırıcılardan ek olarak aldıklarını bildirmiştir. İsrail Ulusal Sağlık ve Beslenme Anketi (MABAT) çalışmasına [24] katılan ve ultrasonografi ile NAYKH tanısı alan 69 bireyin, karaciğer yağlanması bulunmayan gruba (115 kişi) göre fruktozdan zengin alkolsüz gazlı içecekleri 2 kat daha fazla tükettiği saptanmıştır. Ayrıca, alkolsüz gazlı içecek ( $p$ $=0,03)$ ve kırmızı et tüketimi $(p<0,001)$, NAYKH' a yakalanma riski ile ilişkilendirilmiştir. WHO ve $\mathrm{FAO}^{\prime}$ nun 2003 yılındaki 'Diyet, Beslenme ve Kronik Hastalıkları Önleme' raporunda günlük basit şeker alımının (ilave şeker ve bal, şurup ve meyve suyu gibi doğal olarak alınan şekerler), toplam enerjinin \%10' unu geçmemesini tavsiye etmektedir [25].

$\mathrm{Bu}$ çalışmada ise bireylerin fruktoz tüketimleri ile çeşitli değişkenler arasındaki ilişkiye bakıldığında BKi, bel çevresi, bel/kalça oranı, total kolesterol, ürik asit, ALT, AST, ALP, çikolata tüketim miktarı, hazır meyve suyu ve kolalı içecek arasında önemli pozitif bir ilişki belirlenmiştir. Yağlanma derecesi ve fruktoz tüketimi arasında ise kuvvetli düzeyde ilişkinin olduğu ve yağlanmanın derecesi fruktoz tüketim düzeyinin artışıla arttığı görülmüştür.

\section{Çalışmanın Kısıtlılıkları}

NAYKH ve diyet fruktoz ilişkisini inceleyen araştırmalar oldukça kadar azdır. Fruktoz tüketimi ile lipit düzeyleri ve insülin duyarlıı̆̆ındaki ilişkiyi değerlendirebilmek, ayrıca bireylerin NAYKH' ye yakalanmamak için beslenme önerilerinde, diyet fruktoz, HFCS veya sükrozun ne miktarda alınması gerektiğinin netleşmesi açısından randomize kontrollü yeni çalışmalara intiyaç vardır.

\section{Sonuç}

Bu çalışma sonucunda NAYKH'ye sahip bireylerin yağlanma görülmeyen bireylere göre daha fazla fruktoz içeren besinler tükettiği, yağlanma derecesinin arttıkça fruktoz tüketiminin arttığı ve bireylerde fruktoz tüketimin en önemli kaynakları, alkolsüz kolalı içecekler olarak belirlenmiştir Türkiye'de NAYKH'ye sahip bireylerin fruktoz tüketimini saptamaya yönelik veya hangi miktar/çeşitte fruktozun NAYKH'ye yakalanmaya etkisinin olacağına yönelik yapılan sınırlı sayıda çalışma olması nedeniyle, bu çalışmanın fruktoz tüketimi ile NAYKH olan ilişkisini değerlendirmek açısından bir yol gösterici olabileceğı düşünülmektedir.

\section{Çıkar çatışması / finansal destek beyanı}

Bu yazıdaki hiçbir yazarın herhangi bir çıkar çatışması yoktur. Yazının herhangi bir finansal desteği yoktur

\section{Referanslar}

1. Sonsuz A, Baysal B. Karaciğer Yağlanması ve Non Alkolik Steatohepatit. Güncel Gastroenteroloji 2011; 15: 98-106.

2. Falck-Ytter Y, Younossi ZM, Marchesini G, McCullough AJ. Clinical features and natural history of nonalcoholic steatosis syndromes. Semin Liver Dis 2001; 21: 17-26.

3. Çelebi S, Ataseven H, Mengücük E, Deveci S, Açık Y, Bahçecioğlu iH. Elazığ kent toplumunda nonalkolik yağlı karaciğerin epidemiyolojik özellikleri Akademik Gastroenteroloji Dergisi 2006; 5: 41-46.

4. Bayrakçı B, Günşar F. Nonalkolik Steatohepatit. Güncel Gastroenteroloji 2005; 9: 167-76.

5. Baumeister SE, Völzke H, Marschall $P$ et al. Impact of Fatty Liver Disease on Health Care Utilization and Costs in a General Population: A 5-Year Observation. Gastroenterology 2008; 134: 85-94.

6. Gören B, Fen T. Non-Alkolik Yağlı Karaciğer Hastalığı. Turkiye Klinikleri J Med Sci 2005; 25: 841-50.

7. Bedogni G, Miglioli L, Masutti F, Tiribelli C, Marchesini G, Bellentani S. Prevalence of and risk factors for nonalcoholic fatty liver disease: The Dionysos nutrition and liver study. Hepatology 2005; 42: 44-52.

8. White JS. Straight talk about high-fructose corn syrup: what it is and what it ain't. The American Journal of Clinical Nutrition 2008; 88: 1716-21

9. Tappy L, Le KA, Tran C, Paquot N. Fructose and metabolic diseases: new findings, new questions. Nutrition 2010; 26: 1044-49. 
10. Malik VS, Popkin BM, Bray GA, Despres JP, Hu FB. Sugarsweetened beverages, obesity, type 2 diabetes mellitus, and cardiovascular disease risk. Circulation 2010; 121: 1356-64.

11. Bray GA. Soft drink consumption and obesity: it is all about fructose. Current Opinion in Lipidology 2010; 21: 51-7.

12. Ter Horst KW, Schene MR, Holman R, Romijn JA, Serlie MJ. Effect of fructose consumption on insulin sensitivity in nondiabetic subjects: a systematic review and meta-analysis of dietintervention trials. The American Journal of Clinical Nutrition 2016; 104: 1562-76.

13. Ding $X Q, W u, W Y$, Jiao $R Q$ et al. Curcumin and allopurinol ameliorate fructose-induced hepatic inflammation in rats via miR-200a-mediated TXNIP/NLRP3 inflammasome inhibition. Pharmacological Research 2018; 137: 64-75.

14. Yilmaz S, Canpolat U, Baser K, Unal S, Kuyumcu MS, Aydogdu S. Neutrophil-to-lymphocyte ratio predicts functionally significant coronary artery stenosis in patients with stable coronary artery disease. Turk Kardiyoloji Dernegi Arsivi 2018; 46: 129-35.

15. Pekcan G. Beslenme durumunun saptanmasi. Diyet El Kitabi Hatipoglu Yayinevi Ankara 2008; 67-141.

16. Han TS, van Leer EM, Seidell JC, Lean ME. Waist circumference action levels in the identification of cardiovascular risk factors: prevalence study in a random sample. Bmj. 1995; 311: 1401-405.

17. Obesity: preventing and managing the global epidemic. Report of a WHO consultation. World Health Organization Technical Report Series 2000; 894: 1-253.

18. Schofield WN. Predicting basal metabolic rate, new standards and review of previous work. Human nutrition Clinical nutrition 1985; 39: 5-41.
19. Vuppalanchi R, Cummings OW, Saxena R, Ulbright TM, Martis N, Jones DR, et al. Relationship among histologic, radiologic, and biochemical assessments of hepatic steatosis: a study of human liver samples. J Clin Gastroenterol 2007; 41: 206-10.

20. Brzek P, Gebczynski AK, Ksiazek A, Konarzewski M. Effect of calorie restriction on spontaneous physical activity and body mass in mice divergently selected for basal metabolic rate (BMR). Physiology \& Behavior 2016; 161: 116-22.

21. Mahaling DU, Basavaraj MM, Bika AJ. Comparison of lipid profile in different grades of non-alcoholic fatty liver disease diagnosed on ultrasound. Asian Pacific Journal of Tropical Biomedicine 2013; 3: 907-12.

22. Zhang DM, Jiao RQ, Kong LD. High Dietary Fructose: Direct or Indirect Dangerous Factors Disturbing Tissue and Organ Functions. Nutrients 2017; 9.

23. Bray GA, Nielsen SJ, Popkin BM. Consumption of high-fructose corn syrup in beverages may play a role in the epidemic of obesity. The American journal of clinical nutrition. 2004; 79: 537-43.

24. Zelber-Sagi S, Nitzan-Kaluski D, Goldsmith R, Webb M, Blendis L, Halpern Z, et al. Long term nutritional intake and the risk for non-alcoholic fatty liver disease (NAFLD): a population based study. J Hepatol 2007; 47: 711-17.

25. Margetts B. FAO/WHO launch expert report on diet, nutrition and prevention of chronic diseases. Public Health Nutrition 2003; 6: 323-25. 